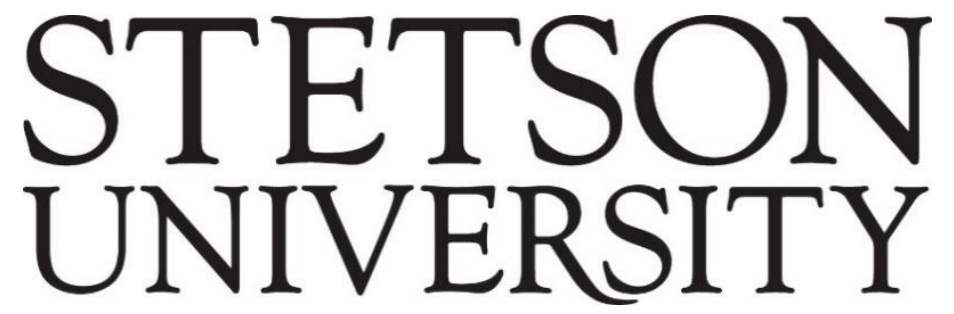

Voices of Reform: Educational Research to Inform and Reform

Volume $1 \bullet$ Issue $1 \bullet$ Article 1

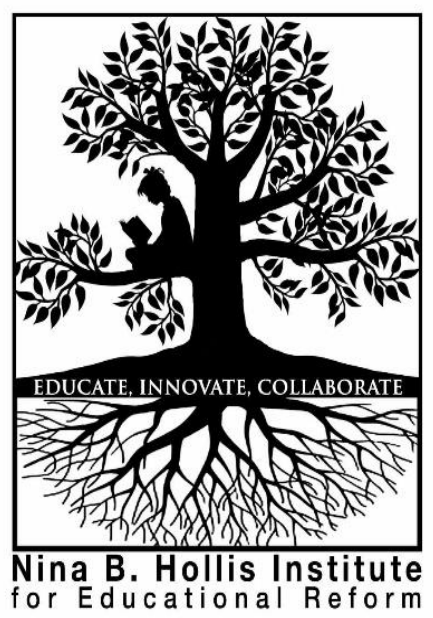

September 2018

Transformation in Teacher Preparation:

Collaborating with School Partners, Enriching

our Programs with High Poverty Urban

Teaching Opportunities

Pamela S. Carroll

University of Central Florida

Follow this and additional works at: http://www.voicesofreform.com

Recommended Citation

Carroll, P. S. (2018). Transformation in teacher preparation: Collaborating with school partners, enriching our programs with high poverty urban teaching opportunities. Voices of Reform, 1(1), 8-22. Retrieved from https://www.voicesofreform.com/article/4484-transformation-in-teacher-preparation-collaborating-with-schoolpartners-enriching-our-programs-with-high-poverty-urban-teaching-opportunities. doi: 10.32623/1.00003

http://dx.doi.org/10.32623/1.00003

Revisions

Submission date: June $1^{\text {st }}, 2018$

$1^{\text {st }}$ Revision: August $1^{\text {st }}, 2018$

Acceptance: August 21 ${ }^{\text {st }}, 2018$

Publication date: September $15^{\text {th }}, 2018$ 


\title{
Transformation in Teacher Preparation: Collaborating with School Partners, Enriching our Programs with High Poverty Urban Teaching Opportunities
}

\author{
Pamela S. Carroll ${ }^{1}$ \\ ${ }^{1}$ College of Community Innovation and Education \\ University of Central Florida, United States \\ pamela.carroll@ucf.edu
}

\begin{abstract}
The teacher preparation programs at University of Central Florida graduates approximately 1,000 prospective teachers annually. They are well prepared for teaching positions in the schools that look like the suburban, middle class ones which most of the teacher candidates attended. They have not been as well prepared for the Title I schools that make up 70\% of the local school system, or to teach the 2,000 homeless children in our area. In 2015, the faculty and administration began working intentionally with school system partners to transform the programs so that they prepare teachers for schools where teachers are most urgently needed: high poverty urban schools. This is the narrative of portions of the early stages of that transformation.
\end{abstract}

\section{Keywords}

urban schools, high-poverty schools, teacher preparation

\section{"No One Told Me I'd Have Homeless Children in My Class"}

It is not a surprise to educators that public school teaching, as a profession, has fallen from favor among secondary school and college students as they choose academic pathways that will prepare them for careers. Teaching is a demanding profession, and professionals are not always offered autonomy as experts, positive working conditions, appropriate salaries and benefits, the respect of supervisors, or appreciation from those whom they serve. Nationally, there was a $29 \%$ decrease in high school students who listed an interest in pursuing a career in education when surveyed while taking the ACT college entrance exam in 2014, and the percentage of college of freshmen interested in a teaching career declined to $4.2 \%$, the lowest level in 45 years, as reported in the Chronicle of Higher Education (Sutcher, Darling-Hammond, Carver-Thomas, 26). 
What may be more surprising is that across the country, many of our teacher education programs have not done more to change our teacher preparation programs in response to changes that have occurred within the communities in the new teachers who graduate from our programs teach. It is true that we regularly monitor and update our programs, but in many ways, our focus has remained primarily inward; we are, legitimately, concerned with the variables that are within our control. We adjust the courses we require, the sequence of field experiences, the systems of monitoring prospective teachers' progress, key transition points. We report graduation, job placement, employee/employer satisfaction rates, and teacher retention rates.

How often, though, do we consider these aspects of our teacher education programs within broader professional and social contexts? When we make adjustments, do we include school system personnel and residents of the communities in which our prospective teachers will work when we consider curricula, field experiences, transition points, job placements, and teacher retention? Do we consider the experiences and needs of the children and their families in our service area when we determine directions for our programmatic changes and modifications?

In the College of Community Innovation and Education at the University of Central Florida, the teacher preparation faculty have been working diligently to improve our teacher preparation programs in order to prepare teachers who are capable and enthusiastic teachers of children and adolescents who attend schools set in high poverty urban schools, like many of those in downtown Orlando. The shift in focus has been intentional, and progress has been propelled by the opportunity presented by the addition of a downtown campus to the University of Central Florida, with education as an academic anchor of the campus.

Our teacher education programs have been traditional in structure, including the following: elementary education; secondary education, with subject content specializations in mathematics, sciences, English language arts, and social studies; and K-12 exceptional education, reading education, art education, world languages education, physical education, and English as a second language. For the group of programs, which are referred to collectively as the Teacher Preparation Programs (TPP) the faculty, administration, and staff, have adopted a three-pronged process for considering how we can transform our good programs; instead of improving them by fixing parts of them, we intend to transform them by changing the nature of them:

- Recognition and support for what we do best

- Alignment of Teacher Preparation Program (TPP) values with needs of high poverty urban schools

- Developing deeper community engagement for significant positive impact

As dean, but also as a long-time teacher educator and former classroom teacher, I have been direct in framing a unit-wide conversation about our role in teacher preparation as an opportunity to, "Lift lives and livelihoods". This phrase is one that UCF President, Dale Whittaker, has identified as a mission of UCF. The College of Community Innovation and Education, and the TPP in particular, is well-poised to draw on our instruction, research, and service to support neighborhoods where there are poverty and other high needs in urban Orlando communities. We 
can refine what we learn as members of the community and refine so that we are more useful partners and neighbors, and so that we can extend lessons to other neighborhoods and other urban education programs, as well. We can demonstrate, when we collaborate with school systems, how education becomes a lever that lifts lives.

Our particular focus, then, became the high poverty urban neighborhoods in Orlando. For each of the prongs of the reconceptualization process, I sought faculty and staff input during town hall meetings and through with written reports on program goals and activities. I have collected and analyzed data support claims about where the programs were having the strongest impact and where they were meeting resistance, and why; the programs conducted formative monitoring of progress, and made modifications to curricula and field experiences as needed, with input from school-system based partners. Everyone involved in the focus on high poverty urban schools shares a tacit understanding that we will honor the expertise of our school system and our community member counterparts, in order to collaborate effectively. We recognize that we are not the experts regarding their communities, but that we can learn from the residents of the communities and improve our programs based on what we learn from them. (see Wilkerson, Chapman, Burnett, \& Carroll, in press, 2018).

\section{Recognition and Support for What We Do Best}

One of the temptations of reform is to try to change everything. Our teacher education programs have been successful in myriad ways. Those who engage in teacher education at UCF have focused in the past few years on enhancing our teacher education programs in several important areas, including these: (1) acknowledging the scale of our partnerships to work toward models of excellence in urban teaching and learning; (2) using technology for teaching, learning, assessment, and communication; (3) improving our ability to address the classroom needs of English language learners (ELs); and (4) increasing information and experience in in exceptional student education for future and practicing teachers.

\section{Scale, Excellence, and Impact}

With approximately 900 teacher preparation completers annually, more certification-ready students graduate from the University of Central Florida than from any other Florida institution of higher education. Prospective teachers can pursue certification in elementary education, secondary subject areas such as mathematics, English language arts, chemistry, biology, physics, and in K12 areas including physical education, exceptional student education, reading, and world languages.

A national decline in teacher education enrollment of approximately 35\% (Sutcher, DarlingHammond, Carver-Thomas, 2016), has been tempered in part at UCF by the unique DirectConnect $^{\mathrm{TM}}$ partnership that the university has developed with six state colleges in the central Florida region (formerly community colleges). Because of DirectConnect ${ }^{\mathrm{TM}}$, we have been able to construct stable and attractive bridges for students to travel across, bridges that connect their high schools to state colleges, then from their state colleges to our university teacher preparation programs. With a guarantee of admission to UCF for students who earn an associate degree from one of six partner state colleges in the central Florida geographic area, and aggressive activity from 
the advising, recruitment, and teacher education programs at our DirectConnect ${ }^{\mathrm{TM}}$ partners and at UCF, enrollments in teacher preparation programs at UCF stabilized and began to increase in 2017.

Through regular meetings, advisors and program directors from the six central Florida counties, and our DirectConnect ${ }^{\mathrm{TM}}$ state college campuses, and UCF TPP, have developed and implemented several unique programs that have similar characteristics. The programs allow prospective teachers to (a) identify interest in teaching as early as high school, (b) take courses toward a teaching major that is specifically aligned with a UCF teaching degree while at a state college, (c) transfer to UCF for the final two years of degree work (and either participate on the main campus or at a regional site), (d) complete pre-internship and student teaching internships in the home county; (e) partially fund prospective teachers during their internships; (f) offer successful program graduates them first choice of teaching positions within their home counties.

\section{Incorporating Technologies}

In the College of Education and Human Performance at UCF, we are especially well-known for incorporating technology into teaching and learning. As one example, when we collaborated with Florida Virtual School (FLVS) in 2011 for virtual internships, we became the first teacher education program in the country to engage in virtual student teaching and evaluation. Since 2011, 389 have completed secondary internships at FLVS, with the peak year in 2013, with 94. We are preparing to set the stage for FLVS elementary education internships, as well, in 2018.

Another example of our innovative uptake of technology is demonstrated by the self-direction of a group of faculty who represent our elementary, secondary, and instructional technology units. During the 2014-15 school year, the ad hoc group formed around their common interest in educational technology. They visited numerous local schools, spoke to technology specialists, and engaged in their own professional development. Learning that many schools were using Google products like Google Classroom, each of the group members attended Google Summits around the country. They also completed all of the modules for the Level 1 Google Certification MicroCredential, Having learned about many features of the Google suite, they worked to embed changes into the courses they teach for elementary education majors.

The most popular pedagogical tool that incorporates technologies across teacher education programs at UCF is TeachLivETM. This product has resulted in a patent, several research projects, publications, local, regional, national and international presentations, applications extended to business, security, and military settings, and commercialization. Dr. Lisa Deiker and Dr. Mike Hynes, professors in the UCF College of Education and Human Performance, and Dr. Charles Hughes, in the UCF College of Engineering and Computer Science, co-developed TeachLivE ${ }^{\text {TM }}$ as a mixed-reality teaching environment that supports teacher practice in classroom management, pedagogy and content. As noted on the Website, teachlive.org:

In the TLE TeachLivETM Lab, pre-service and in-service teachers walk into a room where everything looks like a middle- or high-school classroom including props, whiteboards, and of course, children. However, unlike the brick and mortar setting, the lab is a virtual setting and the students in the classroom are avatars. The virtual students may act like typically developing or not-typically developing students, depending on the objectives of 
the experience. Participants can interact with students and review previous work, present new content to students and provide scaffolding or guided practice in a variety of content areas, and monitor students while they work independently. In an environment like this, prospective teachers can learn the instruction and management skills needed to become effective teachers and practicing teachers can hone and refine their skills....

The TLE TeachLivETM Lab, is currently being used at over 85 campuses in the United States ... The TLE TeachLivETM Lab provides pre-service and in-service teachers the opportunity to learn new skills and to craft their practice without placing "real" students at risk during the learning process.

Research has demonstrated the efficacy of TeachLivE ${ }^{\mathrm{TM}}$ Lab sessions in helping pre-service teachers improve their teaching by giving specific kinds of feedback to the "pupils" (see for example Dawson \& Lignugaris-Kraft, 2016; Barmaki (2015), Barmaki \& Hughes, 2015a,b), Battista \& Boone, 2015), Dieker, L.A., Rodriguez, J., Lingnugaris-Kraft, B., Hynes, M., \& Hughes, C.E. , 2014). (teachlive.org, accessed 15 May 2018.)

Across our Teacher Preparation Programs, technology continues to have a positive impact on the ways that prospective teachers interact with content, with pupils, and with their instructors, thus changing the nature of our programs in positive ways.

\section{Including English Language Learners}

A third area of strength that we recognize and work to support with the College of Education and Human Performance, is the interdisciplinary needs of English learners (ELs). Our English Learner instruction has received an increase in attention since 2016, when the College, in collaboration with the College of Arts and Humanities and schools in Orlando and Tampa, was awarded a grant from the United States Department of Education, Office of English Language Acquisition (OELA) to prepare 100 dual language teachers to work with English language learners, which is the fastest growing sector of the K-12 student population. It is notable that teachers who participate in DL STEPS will use TeachLivE ${ }^{\mathrm{TM}}$ during their EL professional learning.

The DL STEPS research and service project raises important questions that extend to the Teacher Preparation Programs at UCF: What can we learn from this work that will improve our TPPs in order to better prepare teachers to work with high needs populations---students who live in poverty, who have not had school success due to poor instructional records, language differences, housing instability, health challenges, and other barriers?

\section{Embedding Exceptional Student Education into General Education}

In the UCF teacher preparation programs, we seek to prepare teachers to accommodate for and appropriately challenge students with varying exceptionalities who are included in general education classes. Faculty from the Elementary Education program and faculty from the Exceptional Student Education worked together weekly for almost seven months to infuse standards from the Council for Exceptional Children (CEC) into the required courses within the Elementary Education teacher certification program. Together the faculty experts created a plan that gives future teachers of elementary school students a well-developed knowledge of 
exceptionalities, so that they can apply their understanding to their roles as teachers in general education classrooms. As part of the process of learning the content of exceptional education, and how it can be embedded into their courses, each elementary education faculty who would teach a course with embedded exceptional education content enrolled in one or two web-based exceptional education courses, and progressed through the course(s) with the assistance of a peer from the exceptional education program. The collaboration and shared interest in developing a program that prepares the best teachers for today's and tomorrow's classrooms produced an incredibly rich experience for the faculty and administrators who were involved in the faculty-driven, administratively-supported students. This effort, supported financially through the dean's office as a "Fellows Program" primarily during summer term, has led to lasting cooperation and collaboration. The curricular model that the two faculties developed has been highlighted by the Florida Department of Education as an example of best practice. The model, which is now implemented in our elementary education program, serves as one example of the attention that we are giving to exceptional education competencies and the need to incorporate them into the habit of thinking of all teacher candidates as we change the nature of our programs.

\section{Alignment of Teacher Preparation values with Needs of High Poverty Schools}

\section{Facing Today's Realities}

As the new dean of the college in the academic year 2015-2016, I learned, through hosting a series of town hall meetings with the faculty and staff, that student success is central to our sense of mission. We also value collaboration, interdisciplinary and transdisciplinary research, and community engagement. What I also realized as a result of those meetings and while exploring the teacher preparation program with colleagues and students, is that our values were not fully aligned with our practices. We were providing wonderful courses and field experiences for students, while they were in our program, but they did not prepare our students as well as possible for the realities they would find in schools and classrooms where the largest needs exist, where the new teachers can have the most profound impact: high poverty urban schools.

When working in the spring, 2016, with a small group of student teachers, their faculty supervisors, classroom teachers, and administrators from Title One schools in urban Orlando, in an effort to determine what the future and practicing teachers were actually experiencing, however, a different picture was reported. It was in that setting that a student teacher expressed, with frustration and challenge: "No one told me I'd have homeless children in my class" (group discussion, Orlando, FL, February 2016).

Like those in other teacher preparation programs across the country, her words spoke for many of our teacher candidates who anticipate working in schools in which they will find happy learners, new technologies, ample supplies, involved parents, concerned mentors. They envision a smooth, gradual induction into the profession. She was shaken with a lack of confidence when the idealized classroom she had envisioned materialized as a high poverty Title I urban school. Some of the questions that she and her classmates began to voice, at first timidly and then with the conviction that they needed to explore these and other issues in order to understand the context of the schools and communities in which their students live: 
- What does homework mean to a student with no home?

- Is it fair to require a homeless student to participate in a science assignment, when her classmates rely on access to computers at home to prepare for the assignment?

- Should a teacher hold the homeless student to the same academic standards as the other children?

- If standards are relaxed for the homeless student, will she be likely to fall into a cycle of performing below grade level, below expectations?

- What are the long term consequences for the child if her family continues to live in a hotel, or car, or with different friends, in terms of schooling?

- What are the lived experiences of other students who are living in poverty and attending urban schools?

- How do health, nutrition, and environment affect students' academic progress?

- In what positive ways do the high poverty urban schools connect with and support families and the communities around the school?

- What are the strengths that the children and their families bring to the high poverty urban schools that teachers can build upon to work together toward student success?

These are issues that the UCF teacher preparation students, prospective teachers, need to focus on in order for UCF to have an impact on our most significant area of service: high needs urban schools. With enthusiastic participation from some existing faculty groups and the Office of Clinical Field Experiences, the UCF teacher preparation program began to incorporate chances into curricula and filed experiences in order to assure that future teachers had considerable experience in high poverty urban schools during their teacher preparation. Our goal has been that future teachers select Title I schools as their choice for their first teaching positions upon graduation and certification. We have worked diligently with the OCPS to create a series of incentives to promote pathways that encourage movement from the UCF programs through urban school teacher preparation experiences into full time teaching positions, and retention in those positions. We have worked purposefully with colleagues within the area school systems, particularly OCPS, to develop an understanding of the spaces in which children who are living in high poverty urban settings grow up and go to school, so that we can prepare teachers well for the children and adolescents, and so that we can support the families in those neighborhoods as partners in an educational ecosystem.

\section{Creating Community Collaborative Space}

The largest service area for the TPP at UCF is Orlando, Florida, which includes the schools of Orange County Public Schools (OCPS). OCPS is the $9^{\text {th }}$ largest school district in the country, serving approximately 207,000 students with 170 language backgrounds in a primarily metropolitan area. Of its 191 schools, 109, or 57\%, are Title I schools. (ocps.net, accessed 11 May 2018.) Through the OCPS/UCF partnership, we are able to embed prospective teachers into K-12 classrooms in a broad range of experiences, including observation of students and teachers, participation in small group instruction, evaluation of students, and full-time student teaching internships. Through these on-site experiences, our prospective teachers begin to understand the impact of teaching in real time. One of our goals is to prepare new teachers who begin their careers 
with a sense of confidence and knowledge regarding diversity and of communities that are different from the predominant demographic that continues to describe the teaching force in today's schools: white, middle class, Christian, female (Council for the Accreditation of Educator Preparation, Commission on Standards and Performance Reporting, 2013).

In meetings with Superintendent Jenkins and her leadership team at OCPS, I found administrators who were eager to work with UCF teacher education programs to assist us in a shift toward a focus on urban teaching and learning. I was assured that we would be able to accomplish a shift in practice away from assigning student teachers all over the large county, to one that streamlines our focus to the areas where our impact potential is greatest: the high poverty urban core. I was also assured of the OCPS commitment that excellent teachers and school leaders who be in place at those schools to serve as supervisors and mentors for UCF prospective teachers.

The OCPS administrators, DirectConnect ${ }^{\mathrm{TM}}$ state college partners, UCF TPP colleagues, and I began discussing and developing incentives that we would implement to recruit pre-service teachers to the urban schools as "schools of choice" for internships and eventually for full time employment. Scholarships to pay for the required state teachers' test, stipends for serving as teachers' aides upon completion of 108 credit hours toward the 120 credit hours of the teaching major, payment for serving as after-school tutors, guarantee of first offer when a teaching position becomes available in a school system---all of these have been introduced as incentives by our partners in various county school systems.

The Florida Department of Education indicates that the schools with the highest proportion of students who live in poverty are the schools that have the highest number of teachers who are not teaching what they are certified to teach; the statewide average in schools for teachers teaching out of field is $4.3 \%$. In schools that earn an F rating, the percentage of teachers who are teaching out of field (and thus outside of their area of expertise) is almost twice that, at 7.8 \% (FDOE.org, Feb, 2017, 9). Our intention is to use the partnership to defy that statistic, and to see children and adolescents flourish and achieve in good, academically challenging schools, supported by wellprepared, committed teachers, even when the children and adolescents live in poverty.

Our transformation goals have involved the collaborative effort of experts in the school district, area colleges, the local community, and the faculty, administration, and students in our teacher education programs. We share an academic imperative, but also a moral one, and that shared imperative has helped clarify our focus in at least two ways:

(1) We agree that we must prepare future teachers who are qualified to work, and continue to work, successfully with the students whom they will be assigned to teach in the high poverty urban public schools; these are the schools where the need for outstanding teachers is most profound, the majority of teaching positions in our metropolitan service region exist, placement of certified and well-qualified teachers is most difficult, and where attrition is greatest.

(2) We agree that we must prepare future teachers who are culturally aware, knowledgeable, and engaged with the students whom they teach, who understand and respect the histories of the communities in which the schools are located, who develop a deep sense of value of 
their students' lived urban experiences, and who are willing to invest time and effort in the urban community in which they teach, in order to earn standing within the community.

Once the focus of our program began to be transformed by the imperative we share with our OCPS partners, and within the TPP through town hall meetings, smaller group sessions hosted by the college Urban Teaching Special Interest Group, and in in teacher preparation courses, questions emerged:

(1) How can our teacher preparation program best work with the community and school system to address the need for teachers at the places where the need is greatest?

(2) How can our university program work with the community and school system as partners to retain excellent teachers in urban schools, even during teacher preparation?

(3) Which roles and relationships must be institutionalized across the university teacher preparation program, community, and school system in order to guarantee a sustained positive impact on providing well-prepared teachers for high poverty schools in the metropolitan areas of Orlando?

Lee (2018) describes framework for urban teacher preparation that relies on the "development and inclusion of a third space (Norton-Meier \& Drake, 2010) or hybrid space (Zeichner, 2010) where university-based constituents, school and community partners, and families come together" (p. 118). This combination is in place for us at University of Central Florida, where we have the additional strength of local government support, school board acknowledgement of our efforts, and a philanthropic partner whose contributions have allowed families in the neighborhoods to concentrate on academic goals, instead of worrying about how they would pay for child development for their two year olds or college for their graduating high school seniors.

Our particular framework establishes a "community collaborative space". In our revised teacher preparation programs, we are working across UCF, OCPS, City of Orlando, Parramore and Washington Shores neighborhoods (the home of several of our urban school partners), and the Rosen Foundation (host to an two urban preschool-to-college scholarship initiatives, funding for home-based preschools in the Tangelo Park neighborhood, and a preschool that provides for babies-2 year olds who live in the Parramore neighborhoods) to balance the setting so that all participants' voices are heard and actions are noted.

No longer a teacher preparation provider that looks internally to seek evidence of success, we now have a range of initiatives that extend our reach to the communities that we support, and embed those initiatives into the teacher preparation programs. The following provides a snapshot of some of the initiatives that are now included in our programs as a means of increasing attention to the strengths of children, teachers, and communities that house Title One urban schools:

Title 1 School Bus Tour. Upon the recommendation of OCPS, we provide all pre-education majors as well as those who are early in their majors an opportunity, each semester, to join us for a halfday or full-day Tour of Title One Schools. Two OCPS school buses arrive on campus and UCF students board the buses, and are taken to three or more Title I schools. At the schools, they observe teachers while teaching, mingle with students, talk with administrators, have lunch in the 
cafeteria. This Tour has been responsible for debunking many myths about deficiencies that UCF students held regarding the kinds of children, teachers, and staff who populate title one schools, and the environments in which the schools are set.

Carver Middle School. In the spring, 2016, Dr. Bridget Williams, OCPS Chief of Staff, and I attended a conference in Baltimore, Maryland, hosted by the Gates Foundation and Johns Hopkins University Pathways to Adult Success project. The conference focused on preparing students for the transition from high school to college and careers, and as we discussed common goals for the students of Orlando, we developed specific plans. Dr. Williams followed the conference with a request to OCPS for classroom space at one of the urban public schools be used as a teaching laboratory for UCF and Valencia College teacher education students and faculty. The UCF Valencia College Teaching Laboratory was created at Carver K-8. It is currently the site for a weekly class meetings for middle school teachers who are enrolled in the Lockheed Martinsupported K-8 mathematics and science master's degree program offered through the teacher education program at UCF. It is also the site for weekly meetings of a "Support for High Needs Populations," offered by UCF to teachers in the schools in the urban area. Valencia College and UCF use the Teaching Lab as a space in which pre-intern and student teacher college students meet with their cooperating teachers, administrators, and parents, as well.

Others bonds have been established at Carver Middle School, a Title I school in the heart of the high poverty urban area of Orlando, as a result of establishing the Teaching Lab. Notably, a faculty member within the College of Education and Human Performance has become a "Professor in Residence" at Carver Middle, spending one full day a week at the middle school, and usually more. While there, she observes and evaluates the student teachers who are assigned there, but also visits different classrooms in order to interact with the teachers and adolescent students. A long-time resident of Orlando with deep ties to the downtown community, her presence as a trusted adult at the school has become an important feature of the UCF and Carver Middle School partnership.

OCPS ACE Community Partnership School. The kinds of connections that the College of Education and Human Performance and our teacher preparation programs have developed with one of the newest OCPS schools, the Academic Center of Excellence, or ACE, have been shaped by a different set of dynamics than those that have supported the smooth interactions at Carver Middle School (CMS). Whereas CMS has been a central part of the community in which it is located many years, ACE is truly a new school. OCPS ACE is populated by bringing together, for the first time since desegregation, children and young adolescents from the Parramore neighborhoods. Prior to 2016, the children and adolescents of the Parramore neighborhoods were bussed to eleven different elementary, middle, and high schools in order to meet desegregation requirements. For the first time in forty years, OCPS ACE provides a neighborhood school for K$8^{\text {th }}$ graders. Attached to the K-8 school, the Rosen Foundation has built the Rosen Preschool for up to 218 two-four year olds to attend in a home-like environment. Also attached to ACE is a large Boys and Girls Club and, with assistance from the local Orange Blossom Health service, a fully functioning health and dental clinic. OCPS has worked with the Community Partnership Schools Initiative, co-sponsored by UCF and the Florida Children's Home Society, to develop 
ACE using the Community Partnership School model, so that the social services, including health care, social workers, and community services, including assistance regarding parenting and behavioral health, are wrapped into the school's offerings to the students, their families, and all residents of the community.

This model has offered advantages to OCPS ACE, including participation on an Advisory Committee by members of the Community Partnership Schools staff. As the school develops its sense of identity and stability, given the amount of attention and high expectations it has received from the school system and as a contributor to the education ecosystem that is anchored by the UCF and Valencia College Downtown campus, which will open to over 7500 college students in the fall, 2019, it will be an important site for collaboration with the UCF teacher preparation programs. During its first years, however, the more appropriate university-school collaborations are occurring at the advisory level, where planning, progress monitoring, and modifications in ACE school experiences are occurring.

UCF First Star. Because only $10 \%$ of all children who are living in foster care graduate from high school and go to college, and only 35 of those complete college, we in the UCF teacher preparation program identify foster teens as a high needs population that we support through intensive teaching efforts, too. Often those living in foster care have lived in high poverty situations, or have suffered with other complex variables such as violence or housing insecurity too. In 2015, the UCF College of Education and Human Performance, along with the College of Health and Public Affairs, partnered with Community Based Care of Florida and the national non-profit, First Star, to begin to work toward meeting the needs of local teens who are living in the foster care system. Community-Based Care of Central Florida works on behalf of the State of Florida to provide child welfare in the region. It serves more than 3,000 kids daily, providing "foster care, adoption, mentoring, and youth transitional services." (cbccfl.org, accessed 24 May 2018.)

The director of the UCF First Star program, a postdoctoral scholar in Higher Education at UCF, includes faculty and students from the College and across UCF in activities that support the academic, psychosocial, college readiness, and career development of the teens during the academic year, and during the highlight of the program: a four-week intensive summer experience during which the high school students live on the UCF campus and experience academic, socioemotional, physical, and career instruction. It is during the residential experience, in particular, that the students and UCF volunteers who aspire to be teachers, school counselors, principals, and social workers, observe the teens develop a sense of belonging and sharing, as well as a stronger awareness of the significance of education. In 2017, UCF First Star gained significant support in time, attention, and financial support from the non-profit Underdog Dreams, a team of health care and social professionals that is led by a licensed social worker and former foster youth who has achieved his own dreams, and who believes in the potential of the Central Florida students.

Urban Teaching/Urban Education Summits. For several years, Florida House Representative Bruce Antone has been successful in directing an appropriation for "urban teaching' to the University of Central Florida College of Education and Human Performance. In the past three years, the funding has been used strategically to support efforts that bring members of the central Florida community together to explore, from various perspectives, attitudes, practices, barriers, 
and solutions related to urban teaching and learning in our region. In 2015-2016, the funding supported the continuation and growth of the UCF Urban Education Special Interest Group, and its development of a set of graduate courses that have become the Supporting High Needs Populations certificate program. The program is available not only to certified teachers, but to any UCF student who is interested in learning more about the unique circumstances and opportunities that are associated with urban communities and urban learners. We have been particularly careful to develop an asset-based critical framework for the certificate program, in order to dispel the deficit model that is frequently associated with urban education. The certificate program can be earned alone, and is designed so that it can also be added to several master's degree programs as a specialization.

In 2016-2017, and again in 2017-2018, the funding appropriated to UCF for urban teaching was dedicated to the Special Interest group and its monthly meetings, as well as to a major Urban Teaching Summit. In April, 2017, and again in 2018, with the leadership of Dr. Amanda Wilkerson, the summit gathered educational leaders from the central Florida area together with politicians, community thought leaders, business people, teachers, and UCF students and faculty in order to explore topics related to realties of education for children who grow up in poverty or with other extreme needs. Keynote speakers have been Mr. David Johns, former director of the White House Office on Minority Excellence in Education under President Barack Obama, Dr. Pedro Nugero, Distinguished Professor of Education, UCLA, who spent time on campus and visiting schools in the area. The summits included small groups during which action plans were established by groups who have committed to working on behalf of students in high needs school settings in areas such as student-centered instruction, collaboration with diversity, and career and college planning. Progress monitoring is scheduled to begin in the fall, 2018.

Milk and Muffins. No description of UCF involvement with the downtown population would be complete without recognizing the decade of work of the Early Childhood Education program, and its weekly program, Milk and Muffins, a reading experience for young children, held in partnership with the Callahan Parks and Recreation Center and Parramore Kidz Zone. The Mayor of Orlando, Buddy Dyer, has taken note, writing in his newsletter in July 07, 2015, the following:

I'm happy to share that we are partnering with UCF to expand the Parramore Kidz Zone's Milk \& Muffins program that helps increase literacy, enhance children's receptive vocabulary and ensures school readiness among young children in the Parramore neighborhood. (Mayor's Update, Parramore. cityoforlando.net)

Saturday Reading Clinic. Another positive example of instructional work that has been done in the Orlando urban center for decades by UCF teacher preparation faculty and students is the Saturday Reading Clinic. The Saturday Reading Clinic, which began in 2010 with the leadership of the late Dr. Timothy Blair, has given more than 2,500 children free tutoring in reading, and more than 200 parents with an opportunity to participate in the Parent Education Program. Prospective teachers also learn, while giving 90 minute reading lessons, how to assess children's skill and how to present instruction in a culturally responsive way. 


\section{Developing Deeper Community Engagement for Significant Positive Impact}

\section{Creating School Threads to Develop Urban Education}

The list of actions that we can take, in order to work toward improvements in urban education, seems endless. Even though UCF offers the scale of a teacher preparation program that graduates approximately 900-1,000 new teachers annually, and we work closely with the ninth largest school district in the nation, cannot generate answers to persistent questions quickly enough. Nor can we produce new teachers at a fast enough pace to keep pace with the need for teachers. This failure is particularly true in high poverty schools. When school administrators have to put teachers into classrooms to teach subjects for which they are not certified to teach, student learning is at risk. The co-location of high poverty and the failure to staff and retain a qualified teaching faculty, is an equity issue. We at UCF, with our partners, are working to address the trend at the root by helping new teachers become familiar with the high-poverty and also, in many cases, high minority schools in our urban areas.

We recognize an urgency in filling teaching positions with well qualified and enthusiastic teachers--and with those who are committed to staying in urban school settings for several years. Toward that end, we at UCF have refocused and reframed, if not reformed, our teacher preparation programs. We have begun working directly with Orange County Public Schools at the district level since 2015-2016 in more direct ways to align our programs with stated needs of the schools. We engage annually in meetings to develop new strategies for identifying sets of urban schools to which pre-service teachers will be assigned as pre-student teachers (during their penultimate semester) and as student teachers (during their final semester). Called "School Threads" in our plan, these sets will include elementary, middle, and high schools within the same or geographically close neighborhoods and school feeder patterns. All pre-service teachers (preinternship and student teachers) and all classroom-based cooperating teachers within the Thread will be provided time, with a stipend, if possible, to meet as a large group once per month to discuss what they are learning as they focus on the urban children and adolescents of their teaching assignment. These monthly meetings will not focus on classroom lessons per se, but on the larger issues of the impact of the urban environment on children and adolescents as learners. They will also focus on what teachers at all school levels can learn from one another: elementary teachers from middle and high school teachers, high school from elementary, and so on. This perspective is essential to develop, since all pre-service and veteran teachers in a particular Thread are serving children from the same neighborhood or area. Doctoral research will focus on the efficacy of the approach to developing understanding of the impact of environment on education, and the teachers' and pre-service teachers', counselors', and school principals' ability to identify and build on students' strengths as learners, regardless of the background that they bring to the classroom.

Between 2016-2018, the percentage of UCF pre-service teachers who have selected high poverty urban schools as the site of their final semester student teaching internships has increased from a beginning point of approximately $40 \%$ to over $70 \%$ (per conversation with Dr. Bridgett Williams, OCPS Chief of Staff, May, 2018). We consider this $30 \%$ increase a success, and will continue to work together to develop pathways that generate access and energy that motivate future teachers to experience the opportunities that working in urban schools hold for them. 
We are continuing to explore new ways to leverage our scale, to build on our strengths in technology and instruction with the preparation of teachers of English learners, exceptional education and all areas, and to transform our habits of mind so that they we consider the context of schools and pupils' lives when we consider what it means to teach them. We will continue and to work with our partners in high poverty urban school settings and other high needs settings, too, as we transform our Teacher Preparation Programs. Other areas that we are moving into as we seek to transform our TPP, include these, which are at various stages of development:

- An emphasis on STEM and STEAM education that begins in elementary classrooms. Our plan is to create a Makerspace in which practicing and prospective educators can work together to solve problems using problem based learning.

- Arrangements that give attention to earlier and more frequent field experiences that allow our prospective teachers greater access to a broad range of high needs populations, including students with varying disabilities such as those who attend UCP Bailes Elementary, a school in a charter school system with which we partner that has a student population that is divided evenly between normally developing children and children who have intellectual disabilities.

- A consortium for "teaching academies" where representatives from secondary schools, school boards, community colleges, and universities who partner together can meet and exchange ideas and information regarding what works and doesn't related to "grow your own" teacher models that start with students who are in high school.

- A full exploration of the use of micro-credentials in professional learning and in preservice education. We have engaged in lively conversations with district partners who are using micro-credentials in various ways, and are eager to contribute to a research base regarding the efficacy of practices associated with them as tools in teacher professional growth, in preservice learning, and in teacher retention.

- A "pediatric academy" located at Nemours Hospital in which hospitalized children are provided access, through our faculty and students, to interactive learning experiences such as programming robots while learning mathematics and engineering. This collaborative effort will give our faculty opportunities to conduct research on the academic, physiological and psychological impact of learning opportunities on this group of children, as well.

- A space in which prospective teachers of all subjects can observe the physiological impact that good or poor nutrition and various levels of exercise, and other variables, have on the quality of academic experience that their students will have in class, and how these change depending on individual students.

- Use of district school data (at school and individual student level) to inform decisions about how we can better support the needs of our partners through specific interventions and provide other kinds of assistance. 
In the Teacher Preparation Programs at UCF, and with our collaborative partners in the area school systems, we have chosen to work to transform our practices and perspectives---to lead to a change in the nature of our programs---instead of to work toward reform our practices---to lead to an overhaul that suggests fixing broken parts. Yet we realize: Change inevitably raises concerns.

With a focus on high poverty urban schools, do we risk ignoring the needs of other schools, including the suburban ones that we have served well for forty or more years? I have been asked this question several times in the last three years. I believe that we the reach of our TPP is broad and strong enough, at this point in development, to expand to focus on schools that serve high needs populations while also addressing the needs and benefits of other schools. I believe, too, that no one Teacher Preparation Program should strive to do everything. Given our metropolitan location, our identity as a state university, our role as an educational partner for the counties in our region, and our mission to "transform lives and livelihoods" (UCF Collective Impact: Strategic Plan, UCF Board of Trustees, 2016, p. 8), the transformation...the change in the nature...of our TPP from general to focused on support high needs populations, is appropriate, and will continue to develop.

\section{References}

Community Based Care of Central Florida. Retrieved May 24, 2018, from www.cbccfl.org

Council for the Accreditation of Educator Preparation. (2013). Council for the Accreditation of Teacher Educator Report to the Public, the States, the Policymakers, and the Education Profession. Retrieved from https://capenet.org/ media/Files/standards/

Florida Department of Education. Florida Department of Education State High School Graduation Rates. Retrieved May 14, 2018, from www.fldoe.org/core/fileparse.php/7584/urlt/GradRates1617.pdf

Florida Department of Education. Out of Field Teaching. Retrieved May 14, 2018, from FLDOE.org

Ford, T.N., \& Quinn, L. (2010). First year teacher education candidates: What are their perceptions about multicultural education? Multicultural Education, 17, 18-24.

Lee, R.E. (2018). Breaking down barriers and building bridges: Transformative practices in community- and schoolbased urban teacher preparation. Journal of Teacher Education. 69(2), 118-126.

Mayor's Update, Parramore. Retrieved May 13, 2018, from www.cityoforlando.net/mayor/2015/07/

Orange County Public Schools. Retrieved May 11, 2018, from www.ocps.net

Sutcher, L., Darling-Hammond, L., \& Carver-Thomas, D. (2016). A coming crisis in teaching? Teacher supply, demand, and shortages in the U.S., Palo Alto, CA: Learning Policy Institute.

TLE TeachLive ${ }^{\mathrm{TM}}$. Retrieved May 15, 2018, from teachlive.org/publications

UCF Board of Trustees. (2016). UCF Collective Impact: Strategic Plan.

UCF Today. Retrieved May 22, 2018, from https://edcollege.ucf.edu/2017/10/

Wilkerson, A., Chapman, D., Bennett, J., \& Carroll, P. (in press). Shifting our focus: Collaborating with urban schools to support African American students. Urban Education Policy and Research Annual. 